\title{
Pure laparoscopic unilateral nephrectomy for a patient with a polycystic horseshoe kidney
}

\author{
Shawn Dason, MD; Christopher B. Allard, MD, FRCSC; Bobby Shayegan, MD, FRCSC; \\ Kevin Piercey, MD, FRCSC
}

Division of Urology, McMaster University, Hamilton, ON

Cite as: Can Urol Assoc J 2014;8(11-12):e881-3. http://dx.doi.org/10.5489/cuaj.1919 Published online November 24, 2014.

\section{Abstract}

A 45-year-old female patient with autosomal dominant polycystic kidney disease (ADPKD) and a horseshoe kidney underwent right laparoscopic nephrectomy. The indication for nephrectomy was to create space within the right iliac fossa for renal transplantation. The operation proceeded as routine for laparoscopic nephrectomy for ADPKD, but was uniquely challenging due to the large size and extensive vasculature of the polycystic horseshoe kidney. In addition to documenting the feasibility of the pure laparoscopic approach for nephrectomy in patients with ADPKD and horseshoe kidney, this case highlights the abnormal location and vasculature encountered when operating on horseshoe kidneys.

\section{Introduction}

Autosomal dominant polycystic kidney disease (ADPKD) results from a mutation in PKD1 (85\%) or PKD2 (15\%) causing cysts in the kidney and often leading to end-stage renal disease (ESRD). ${ }^{1}$ ADPKD has a prevalence of 1 in 400 to 1 in $4000 .{ }^{1}$ Horseshoe kidney is a congenital anomaly resulting from the fusion of 2 kidneys; it has a prevalence of about 1 in $474 .{ }^{2}$ Concurrent ADPKD and horseshoe kidney is very rare, with less than 20 cases reported and an estimated prevalence of 1 in 134000 to 1 in $8000000 .{ }^{3}$ Patients with ADPKD often require native nephrectomy for indications that include making space within the iliac fossa for renal transplantation, proteinuria, infection, symptoms from mass effect, urolithiasis or tumours. ${ }^{4}$ Laparoscopic nephrectomy in ADPKD is technically challenging due to renal size, but has benefits that include low morbidity, short hospital stay, and a fast recovery. ${ }^{5}$ We present the first reported case of a unilateral pre-transplant pure laparoscopic nephrectomy performed for a polycystic horseshoe kidney.

\section{Case history}

A 45-year-old woman with ESRD secondary to ADPKD was evaluated for native nephrectomy due to insufficient space within the iliac fossa for renal transplantation (Fig. 1). She had no history of peritoneal dialysis use and her prior abdominal surgeries included an open cholecystectomy and 2 Cesarean sections. Relevant medical comorbidities included ESRD and chronic obstructive pulmonary disease managed medically with no home oxygen use. Her only history of urinary tract infection was a single episode of Klebsiella septicemia. She was minimally symptomatic from her polycystic kidneys and blood pressure and proteinuria were wellcontrolled. When the primary indication for nephrectomy is to provide space for future renal transplant, it is the practice at our centre to perform unilateral nephrectomy. The right kidney is preferentially removed due to our preference for right iliac fossa transplantation.

\section{Description of operative procedure}

The right laparoscopic nephrectomy proceeded with the patient in the left lateral decubitus position. Pneumoperitoneum was achieved by Veress needle insufflation at the umbilicus. A 10 to $12-\mathrm{mm}$ camera port was inserted at the umbilicus. Adhesions from the patient's previous abdominal surgeries were encountered lysed following placement of a 10 to $12-\mathrm{mm}$ trocar in the right lower quadrant slightly inferior to the umbilicus. A 5-mm trocar was placed in the right upper quadrant and an additional 5-mm sub-xiphoid port was placed for cephalad liver retraction.

Right renal exposure was performed with hook electrocautery by mobilizing the colon along the White Line of Toldt and Kocherizing the duodenum. Horseshoe configuration was confirmed intraoperatively and both ureters were seen to be draped anteriorly over the malrotated kidney (Fig. 2). Lateral and hepatorenal attachments were divided. Dissection of the 


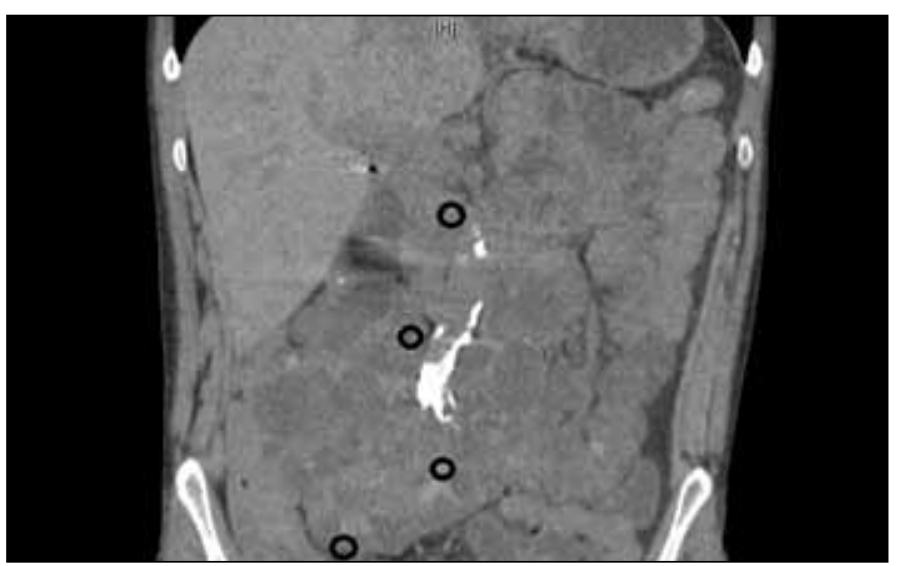

Fig. 1. Ultrasound image demonstrating right and left polycystic kidneys with echogenic isthmus.

renal vasculature proceeded from the level of the duodenum in a caudal direction towards the level of the inferior mesenteric artery, where the isthmus was encountered (Fig. 3). During this dissection, 7 distinct renal vessels were identified, clipped, and divided. Following division of all renal vessels, the ureter was divided between titanium clips.

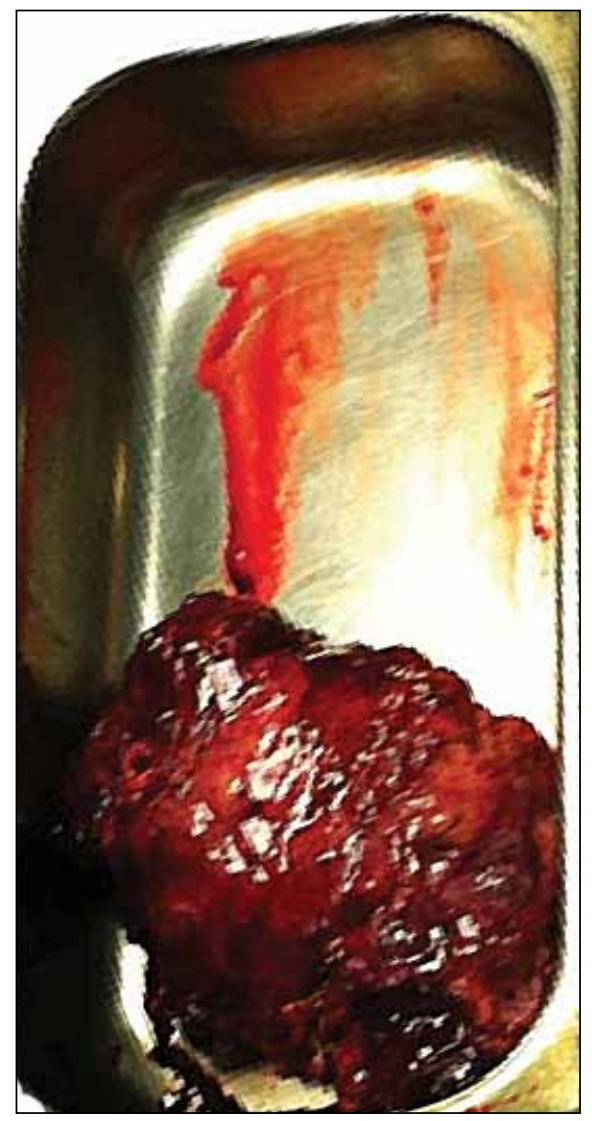

Fig. 3. Photograph of the removed kidney.

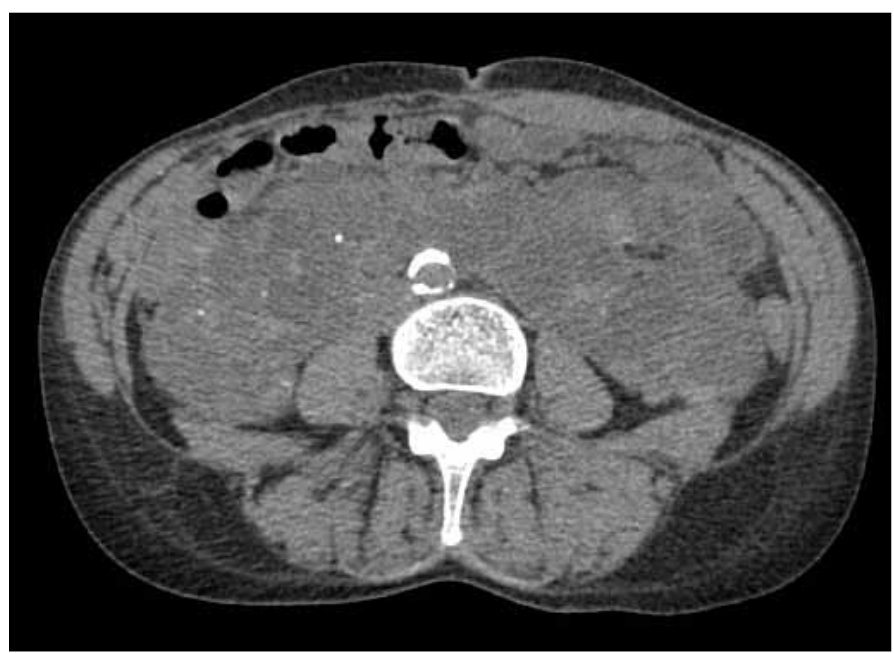

Fig. 2. Axial computed tomography image demonstrating polycystic horseshoe kidney.

A port site was extended to $10 \mathrm{~cm}$ to facilitate removal of the specimen. Through this extraction site, the renal isthmus was ligated with silk ties and divided sharply prior to specimen removal. The specimen was extracted weighing $491 \mathrm{~g}$ and measuring $18 \times 10 \times 6.5 \mathrm{~cm}$ (Fig. 4). The patient had an uneventful recovery and was discharged on postoperative day 3. No postoperative complications were encountered in follow-up and the patient is currently awaiting transplantation.

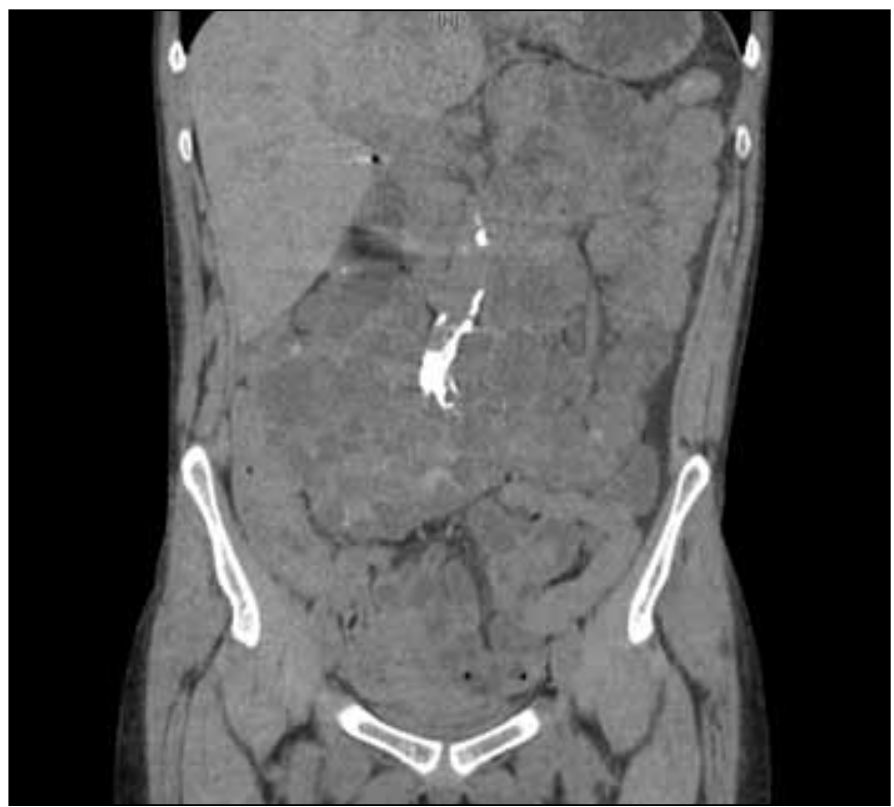

Fig. 4. Coronal non-contrast computed tomography image demonstrating polycystic horseshoe kidney which occupies most of the abdomen and extends below the iliac crests. Circles mark approximate laparoscopic port sites. 


\section{Discussion}

To our knowledge, this is the first description of a pure laparoscopic approach to unilateral nephrectomy for ADPKD in a horseshoe kidney. The isthmus was divided through the extraction site incision, the size of which was as small as possible to allow specimen removal $(10 \mathrm{~cm})$. The laparoscopic approach for pre-transplant nephrectomy for ADPKD has potential benefits, including shorter hospital stay, decreased analgesia requirements, and minimal blood loss. ${ }^{5-7}$

This case highlights the challenges of operating on a horseshoe kidney. On top of the lack of a familiar orientation and location, horseshoe kidneys are joined by a fibrous isthmus in the midline and are frequently supplied by aberrant and numerous vessels. In a review of the imaging findings in 185 horseshoe kidneys, ${ }^{2}$ there were an average of 2.4 and 1.9 right and left renal arteries, respectively. There were 2.4 and 1.7 right and left renal veins, respectively. Severe anomalies or malformations were found in $23 \%$ of these patients with half in the urogenital system. This variable anatomy presents an added challenge to that of operating on large ADPKD kidneys.

\section{Conclusion}

Pure laparoscopic nephrectomy for ADPKD is feasible. Adequate review of preoperative imaging and awareness that difficult anatomy will be encountered are felt to be critical in this operation.
Competing interests: Dr. Dason, Dr. Allard, Dr. Shayegan and Dr. Piercey all declare no competing financial or personal interests.

This paper has been peer-reviewed.

\section{References}

1. Torres VE, Harris PC, Pirson Y. Autosomal dominant polycystic kidney disease. Lancet 2007;369:1287301. http://dx.doi.org/10.1016/S0140-6736(07)60601-1

2. Glodny B, Petersen J, Hofmann KJ, et al. Kidney fusion anomalies revisited: Clinical and radiological analysis of 209 cases of crossed fused ectopia and horseshoe kidney. BJU Int 2009; 103:224-35. http://dx.doi. org/10.1111/i.1464-410X.2008.07912.x

3. Brum FA, Becker M, Uglione A, et al. Polycystic horseshoe kidney. J Urol 1997;158:2229. http:// dx.doi.org/10.1016/S0022-5347(01)68207-7

4. Wein AJ, Kavoussi LR, Campbell MF. Campbell-Walsh Urology. 10th ed. Philadelphia, PA: Elsevier Saunders; 2012.

5. Binsaleh S, Al-Enezi A, Dong J, et al. Laparoscopic nephrectomy with intact specimen extraction for polycystic kidney disease. J Endourol 2008;22:675-80. http://dx.doi.org/10.1089/end.2007.0147

6. Desai MR, Nandkishore SK, Ganpule A, et al., Pretransplant laparoscopic nephrectomy in adult polycystic kidney disease: A single centre experience. BJU Int 2008;101:94-7.

7. Verhoest $G$, Delreux $A$, Mathieu $R$, et al. Transperitoneal laparoscopic nephrectomy for autosomal dominant polycystic kidney disease. JSLS 2012;16:437-42. http://dx.doi.org/10.4293/1086808 $12 \times 13462882736178$

Correspondence: Dr. Shawn Dason, Division of Urology, McMaster University, Hamilton, ON; shawn.dason@medportal.ca 